\title{
Weight and Health Behaviour Changes among Ageing People with Medication for Hypertension and High Cholesterol Level
}

\author{
Tommi Sulander, ${ }^{1,2}$ Heikki Heinonen, ${ }^{3}$ Antti Karisto, ${ }^{1}$ Raisa Valve, ${ }^{4}$ Pertti Pohjolainen, ${ }^{2}$ \\ Ullamaija Seppälä, ${ }^{1}$ and Mikael Fogelholm ${ }^{5}$ \\ ${ }^{1}$ Department of Social Research, University of Helsinki, P.O. Box 18, 00014 Helsinki, Finland \\ ${ }^{2}$ Age Institute, Asemapäällikönkatu 7, 00520 Helsinki, Finland \\ ${ }^{3}$ Department of Lifestyle and Participation, National Institute for Health and Welfare, P.O. Box 30, 00271 Helsinki, Finland \\ ${ }^{4}$ Palmenia Centre for Continuing Education, University of Helsinki, Saimaankatu 11, 15140 Lahti, Finland \\ ${ }^{5}$ Department of Food and Environmental Sciences, University of Helsinki, P.O. Box 62, 00014 Helsinki, Finland
}

Correspondence should be addressed to Tommi Sulander, tommi.sulander@helsinki.fi

Received 7 December 2011; Accepted 29 December 2011

Academic Editor: J. Konde-Lule

Copyright (c) 2012 Tommi Sulander et al. This is an open access article distributed under the Creative Commons Attribution License, which permits unrestricted use, distribution, and reproduction in any medium, provided the original work is properly cited.

Purpose. It is hypothesized that people with medication for hypertension and/or high cholesterol level do not lose weight or change their health behaviour. Methods. This is a six-year follow-up study consisting of 1,428 individuals from two birth cohorts (1936-40, 1946-50) who took part in clinical check-ups and answered to the survey questionnaires in 2002 and 2008. Results. Those participants, born in 1946-50, who had medication at the baseline had higher increase of body mass index $(P<0.01)$ and waist circumference $(P<0.01)$ at the follow-up. No major disparities in health behaviour changes between medicated and nonmedicated were found. Conclusions. Findings of this study support partly the hypothesis that aging individuals with medication for hypertension and/or high cholesterol level do not lose weight or change their health behaviour.

\section{Introduction}

Hypertension and high cholesterol level are the most common cardiovascular risk factors requiring long-term drug therapy $[1,2]$. Evidence from the past few decades shows that pharmacotherapy of hypertension and high cholesterol level reduces cardiovascular mortality and morbidity [2-5]. A recent evidence shows reductions of total cholesterol and systolic blood pressure to be important risk factor changes to decrease coronary heart disease mortality [6].

Positive changes in people's health behaviour play an important role in prevention of hypertension and high cholesterol level. Especially physical activity and healthy diet with low amount of saturated fat and frequent consumption of vegetables have positive effect on levels of blood pressure and cholesterol [7]. Furthermore prospective epidemiological studies have shown clear relationship of overweight and obesity with cardiovascular morbidity and mortality [8-10].

There are a very few studies examining health behaviour changes among people who are under medication for hypertension and high cholesterol level. A recent study from UK found out that cardiovascular medication is linked with lower uptake of health-enhancing physical activity [11]. It is also suggested that those people who begin use of statin therapy do not change significantly saturated fat intake after a six-month follow-up [12]. According to these findings, we hypothesized that people with medication for hypertension and/or high cholesterol level do not change their health behaviour, which is indicated by fat intake, physical activity, and weight loss.

\section{Methods}

2.1. Subjects. The analyses are based on the Good Aging in the Lahti Region (GOAL) program: a longitudinal study where three birth cohorts (born in 1926-1930, 1936-1940, and 1946-1950) will be followed up during 10 years (200212). The baseline study including survey questionnaire and clinical check-ups was conducted in 2002 with the target sample of 4,272 persons. The participation rate was $66 \%$ 
$(n=2,815)$. The design and the sample of the study have been described in more detail elsewhere [13]. In the present study, participants in the two youngest age cohorts (1936-40 and 1946-50) who took part in the clinical check-ups and answered to the survey in 2002 and 2008 were analysed $(n=$ $1,428)$. The oldest age cohort was pooled out from the analyses as body weight among the older adults tends to decrease along ageing due to the physiological changes in the body.

2.2. Measures. As a part of the clinical check-ups, body mass index (BMI) was calculated as measured weight $(\mathrm{kg})$ divided by the square of measured height $\left(\mathrm{m}^{2}\right)$. Waist circumference (WC) was measured by locating the upper hip bone and placing a measuring tape around the abdomen (ensuring that the tape measure was horizontal). BMI and WC were used as continuous variables in the analyses.

Usage of medication for hypertension and/or high cholesterol was based on self-reports, classified into four categories: (1) medication for hypertension, (2) medication for high cholesterol, (3) medication for hypertension and high cholesterol, and (4) no medication.

Physical activity was assessed based on a question: "how much do you practice physical activity and strain yourself physically on your spare time? If physical strain varies a lot during seasons, mark the alternative which best describes your average situation?" This question was measured using a four-point scale: (1) I mainly sit and perform tasks that do not require much physical activity nor physical strain, (2) I walk, cycle, or do other moderate-intensity physical activities at least 4 hours per week, (3) I am engaged in fitness exercise training at least 3 hours per week, and (4) I train for competitive sports several times per week.

Participants were asked about the type of fat used on the bread and in cooking. A two-item variable was constructed to represent use or avoidance of saturated fat. Both variables were dichotomised as $0=$ avoidance of saturated fat (butter, butter-oil mixture, and hard margarine) and $1=$ use of saturated fat. Use of vegetables was dichotomised as $0=$ daily use and 1 = less than daily use.

Sociodemographic variables were used mainly for control purposes in the analyses. These included gender, age, education, marital status, and area of living. Categories of these variables and distribution (\%) of sociodemographic factors and medication groups are shown in Table 1.

2.3. Statistical Methods. Repeated-measures ANOVA [14] was used to detect any univariate differences in BMI, WC, and physical activity between medication groups. Means of BMI, WC, and physical activity (PA) for medication groups at baseline and follow-up are reported in Table 2. Usage of saturated fat and vegetables was measured using categorical variables. This is why binary logistic regression analysis was employed to predict their usage in the medication groups. Results from the binary logistic regression were quoted only in the text.

2.4. Ethical Considerations. The studies will not entail any significant foreseeable risk or harm to the participants' health
TABLE 1: Distribution of sociodemographic factors and medication groups by age cohort (\%).

\begin{tabular}{|c|c|c|c|}
\hline & \multicolumn{2}{|c|}{ Cohort } \\
\hline & & $1946-1950$ & 1936-1940 \\
\hline & & $n=665$ & $n=763$ \\
\hline \multirow{2}{*}{ Gender } & Men & 43 & 47 \\
\hline & Women & 57 & 53 \\
\hline \multirow{4}{*}{ Marital status } & Married & 80 & 76 \\
\hline & Divorced & 10 & 11 \\
\hline & Widow(er) & 3 & 8 \\
\hline & Unmarried & 7 & 5 \\
\hline \multirow{3}{*}{ Education } & $\begin{array}{c}\text { Elementary } \\
\text { school }\end{array}$ & 63 & 76 \\
\hline & Middle school & 23 & 16 \\
\hline & $\begin{array}{c}\text { Secondary } \\
\text { school }\end{array}$ & 14 & 8 \\
\hline \multirow{4}{*}{ Medication 2002} & Hyp. & 14 & 21 \\
\hline & Chol. & 3 & 8 \\
\hline & Hyp. + Chol & 3 & 9 \\
\hline & No med. & 80 & 61 \\
\hline \multirow{4}{*}{ Medication 2008} & Hyp. & 20 & 23 \\
\hline & Chol. & 11 & 14 \\
\hline & Hyp. + Chol & 11 & 21 \\
\hline & No med. & 58 & 43 \\
\hline
\end{tabular}

or well-being. The anonymity of the participants is secured as this study will not produce any individual level information. All the participants have been precisely informed about the aims of the project and what does it mean to participate in this project. After this they have signed written consent. The protocols have been reviewed by the ethical committees of the Päijät-Häme Central Hospital (PHCH), Finland, and the National Institute of Health and Welfare, Finland.

\section{Results}

From 2002 to 2008 the mean BMI increased 0.7 units and mean WC 2.2 centimetres among the youngest birth cohort. Corresponding figures for the older birth cohort were 0.2 and 1.0. Approximately every fifth of the respondents reported using saturated fat on bread both in 2002 and 2008. Averagely one out of four respondents reported using saturated fat in cooking in 2008 and its use attenuated slightly during the follow-up. Approximately two out of three respondents in 2002 and 2008 informed that they do not use fresh vegetables daily (results in this paragraph are not shown in tables).

A significant time-by-group interaction was observed for both BMI and WC among the youngest birth cohort, that is, the baby boomers (the date well covers the baby boomers, who in Finland were born immediately after World War II and during a short time span). Those baby boomers who had medication at the baseline in comparison to those without medication had higher increase of BMI $(P<0.01)$ and WC $(P<0.01)$ at the follow-up (Table 2$)$. The highest mean 
TABLE 2: Mean body mass index (BMI), mean waist circumference (WC), and physical activity (PA) scores for two age cohorts in different medication groups at baseline and follow-up ${ }^{\mathrm{a}}$.

\begin{tabular}{|c|c|c|c|c|c|c|c|}
\hline \multirow{2}{*}{ Cohort } & & \multicolumn{6}{|c|}{ Medication 2002} \\
\hline & & Hyp (SD) & Chol (SD) & $\begin{array}{l}\text { Hyp + Chol } \\
\text { (SD) }\end{array}$ & $\begin{array}{l}\text { No med } \\
\text { (SD) }\end{array}$ & $\begin{array}{c}F \text {-values, degrees } \\
\text { of freedom }\end{array}$ & $\begin{array}{c}\text { Pairwise } \\
\text { Comparisons }^{\mathrm{b}}\end{array}$ \\
\hline \multirow{9}{*}{ 1946-1950 } & BMI 2002 & $29.1(5.4)$ & $26.7(3.0)$ & $29.6(4.0)$ & $26.7(4.2)$ & \multirow{3}{*}{$5.36^{* *}, \mathrm{df}=3,602$} & $\begin{array}{c}\mathrm{NM}<\mathrm{H}, \\
\mathrm{NM}<\mathrm{HC}, \\
\mathrm{C}<\mathrm{H}, \mathrm{C}<\mathrm{HC}\end{array}$ \\
\hline & BMI 2008 & $30.2(5.7)$ & $28.2(3.4)$ & $31.6(5.8)$ & $27.4(4.2)$ & & \multirow{8}{*}{$\begin{array}{c}\mathrm{NM}<\mathrm{H}, \\
\mathrm{NM}<\mathrm{HC}, \\
\mathrm{C}<\mathrm{H}, \mathrm{C}<\mathrm{HC}\end{array}$} \\
\hline & mean dif. & $1.1(0.3)$ & $1.5(0.4)$ & $2.0(1.7)$ & $0.7(0.0)$ & & \\
\hline & WC 2002 & $96.7(13.0)$ & $93.2(13.2)$ & $104.1(13.2)$ & $92.1(12.2)$ & & \\
\hline & WC 2008 & $99.5(13.8)$ & $97.6(14.5)$ & $109.9(15.6)$ & $94.1(13.0)$ & \multirow[t]{3}{*}{$5.15^{* *}, \mathrm{df}=3,602$} & \\
\hline & mean dif. & $2.8(0.8)$ & $3.4(1.3)$ & $5.8(2,4)$ & $2.0(0.8)$ & & \\
\hline & PA 2002 & $2.0(.6)$ & $2.2(.5)$ & $2.1(.6)$ & $2.0(.6)$ & & \\
\hline & PA 2008 & $2.0(.7)$ & $2.2(.5)$ & $2.4(.7)$ & $2.2(.6)$ & \multirow[t]{2}{*}{$1.40^{\mathrm{ns}}, \mathrm{df}=3,603$} & \\
\hline & mean dif. & $0.0(.1)$ & $0.0(.0)$ & $0.3(.1)$ & $0.2(.0)$ & & \\
\hline \multirow{9}{*}{ 1936-1940 } & BMI 2002 & $29.8(5.1)$ & $27.4(3.9)$ & $30.0(4.0)$ & $27.0(4.1)$ & \multirow{3}{*}{$2.26^{\mathrm{ns}}, \mathrm{df}=3.709$} & \multirow{9}{*}{$\mathrm{H}>\mathrm{NM}, \mathrm{H}>\mathrm{C}$} \\
\hline & BMI 2008 & $30.4(5.7)$ & $27.5(4.1)$ & $29.8(4.6)$ & $27.0(4.2)$ & & \\
\hline & mean dif. & $0.6(0.6)$ & $0.1(0.2)$ & $-0.2(0.6)$ & $0.0(0.1)$ & & \\
\hline & WC 2002 & $100.2(13.0)$ & $94.9(10.6)$ & $101.5(10.5)$ & $92.6(12.6)$ & \multirow{3}{*}{$2.00^{\mathrm{ns}}, \mathrm{df}=3,704$} & \\
\hline & WC 2008 & $102.6(14.0)$ & $95.9(10.9)$ & $102.4(10.8)$ & $93.2(12.8)$ & & \\
\hline & mean dif. & $2.4(1.0)$ & $1.0(0.3)$ & $0.9(0.3)$ & $0.6(0.2)$ & & \\
\hline & PA 2002 & $1.9(.5)$ & $2.1(.6)$ & $2.0(.6)$ & $2.1(.6)$ & \multirow{3}{*}{$1.70^{\mathrm{ns}}, \mathrm{df}=3,658$} & \\
\hline & PA 2008 & $2.1(.6)$ & $2.2(.6)$ & $2.2(.7)$ & $2.2(.6)$ & & \\
\hline & mean dif. & $0.2(.1)$ & $0.1(.0)$ & $0.2(.1)$ & $0.1(.0)$ & & \\
\hline
\end{tabular}

${ }^{\mathrm{a}}$ Repeated-measures ANOVA examining between group differences and time-by-group interactions.

Adjusting for gender, marital status, education, and hypertension/cholesterol medication in 2008.

$* * P<0.01$.

${ }^{b}$ Statistically significant between group differences; < indicates lower increase in BMI or waist circumference. NM: no medication, H: medication for hypertension, C: medication for high cholesterol, and HC: medication for hypertension and high cholesterol.

WC increase (5.7 centimetres) was seen among those who had medication for both hypertension and high cholesterol at the baseline. Pairwise comparison showed that those with no medication and those with cholesterol medication had lower increase of BMI and WC than those in other categories. Furthermore, those with medication for hypertension and for both hypertension and cholesterol had similar increase of BMI and WC (Table 2).

There were no major changes or disparities in physical activity between medication groups.

The binary logistic regression analysis revealed that, among the baby boomers, the use of saturated fat had increased significantly in the group of hypertension medication in comparison to those without medication. Use of vegetables did not change significantly between medication groups (data not shown). Adjusting for sociodemographic variables did not have any major effect on these results.

For older birth cohort WC change was smaller among those receiving hypertension medication compared to those without medication and with cholesterol medication. There were no major changes or disparities in health behaviours between medication groups among those born in 1936-40.

\section{Discussion}

Our findings support partly the hypothesis that individuals with medication for hypertension and/or high cholesterol level do not lose weight or change their health behaviour.

The hypothesis got support especially among the baby boomers.

In spite that most of the physicians report that they usually follow at least one set of clinical guidelines for primary cardiovascular disease (CVD) prevention [15], the present study together with previous studies $[11,12]$ gives evidence that people do not change their health-related behavior which is part of the recommendations attached to the guidelines. It is essential to use drug therapy for lowering risk levels, for example, among those who have a genetic predisposition to CVD. On the other hand, continuing unhealthy behaviour together with drug treatment may lead to a double burden. For instance most of the smokers and obese individuals attain balanced blood pressure and cholesterol level using appropriate medication and may therefore feel to be protected. At the same time smoking and obesity both increase the risk of CVD and many other 
diseases. In this sense medication may rock one into a false sense of security.

In a study conducted by Stamatakis et al. [11] those adults with cardiovascular medication were physically more inactive than those without medication. In the present study no such disparity was found. One explanation for the discrepancy between these studies could be different questions on physical activity and also the different age span of the studied populations. Our results are partly in line concerning previous evidence on unchanged saturated fat intake among people who use statins [12].

Even though the data used in the present study is not representative at the national level, the circumstances in the study area do not differ much from the national averages. One of the strengths of the data is its longitudinal, rather than cross-sectional, design. As the information from the use of medication and health behaviours was based on self-reports, we could not fully eliminate the possible selfreport bias as a contribution to our findings. Although the leisure-time physical activity used lacks validation, a comprehensive review has shown that no single physical activity questionnaire has proven superior [16]. Due to the data we were not able to analyze dietary fat more thoroughly. However, the questions used are the same that have been assessed in major Finnish population studies [17].

Even though medication for hypertension has led to impressive cut in the incidence of strokes [18], health behaviour to reduce the risk for hypertension should not be forgotten (reduced salt intake, increased potassium intake by eating more fruit and vegetables, cut smoking, reduced alcohol consumption, and increased exercise) [17]. Also weight loss should be a top of intervention strategies as it has positive impact on level of blood pressure and cholesterol [19]. These behaviour modifications also have the advantage of improving the patient's quality of life. As the relationship between health behaviour and increased risk for certain chronic diseases has been well established, results from the present study emphasize the importance of primary health care to take more active role in health promotion.

\section{Conflict of Interests}

The authors declare that there are no conflicts of interest.

\section{References}

[1] A. D. Lopez, C. D. Mathers, M. Ezzati, D. T. Jamison, and C. J. Murray, "Global and regional burden of disease and risk factors, 2001: systematic analysis of population health data," The Lancet, vol. 367, no. 9524, pp. 1747-1757, 2006.

[2] World Health Organisation, Prevention of Cardiovascular Disease: Guideline for Assessment and Management of Cardiovascular Risk, World Health Organization, Geneva, Switzerland, 2007.

[3] B. Dahlöf, L. H. Lindholm, L. Hansson, B. Schersten, T. Ekbom, and P. O. Wester, "Morbidity and mortality in the Swedish trial in old patients with hypertension (STOPHypertension)," The Lancet, vol. 338, no. 8778, pp. 1281-1285, 1991.

[4] G. Greenberg, "MRC trial of treatment of mild hypertension: principal results," British Medical Journal, vol. 291, no. 6488, pp. 97-104, 1985.

[5] K. Pyörälä, C. M. Ballantyne, B. Gumbiner et al., "Reduction of cardiovascular events by simvastatin in nondiabetic coronary heart disease patients with and without the metabolic syndrome: subgroup analyses of the Scandinavian Simvastatin Survival Study (4S)," Diabetes Care, vol. 27, no. 7, pp. 17351740, 2004.

[6] H. C. Wijeysundera, M. Machado, F. Farahati et al., "Association of temporal trends in risk factors and treatment uptake with coronary heart disease mortality, 1994-2005," Journal of the American Medical Association, vol. 303, no. 18, pp. 18411847, 2010.

[7] P. Puska, E. Vartiainen, T. Laatikainen, P. Jousilahti, and M. Paavola, Eds., The North Karelia Project. From North Karelia to National Action, University Printing House, Helsinki, Finland, 2009.

[8] G. Hu, J. Tuomilehto, K. Silventoinen, N. Barengo, and P. Jousilahti, "Joint effects of physical activity, body mass index, waist circumference and waist-to-hip ratio with the risk of cardiovascular disease among middle-aged Finnish men and women," European Heart Journal, vol. 25, no. 24, pp. 22122219, 2004.

[9] D. L. McGee, "Body mass index and mortality: a meta-analysis based on person-level data from twenty-six observational studies," Annals of Epidemiology, vol. 15, no. 2, pp. 87-97, 2005.

[10] A. G. G. Turpie, K. A. Bauer, B. I. Eriksson, and M. R. Lassen, "Overweight and obesity as determinants of cardiovascular risk: the Framingham experience," Archives of Internal Medicine, vol. 162, no. 16, pp. 1867-1872, 2002.

[11] E. Stamatakis, M. Hamer, and P. Primatesta, "Cardiovascular medication, physical activity and mortality: cross-sectional population study with ongoing mortality follow-up," Heart, vol. 95, no. 6, pp. 448-453, 2009.

[12] D. M. Mann, J. P. Allegrante, S. Natarajan, V. M. Montori, E. A. Halm, and M. Charlson, "Dietary indiscretion and statin use," Mayo Clinic Proceedings, vol. 82, no. 8, pp. 951-953, 2007.

[13] M. Fogelholm, R. Valve, P. Absetz et al., "Rural-urban differences in health and health behaviour: a baseline description of a community health-promotion programme for the elderly," Scandinavian Journal of Public Health, vol. 34, no. 6, pp. 632640, 2006.

[14] J. P. Stevens, Applied Multivariate Statistics for the Social Sciences, Lawrence Erlbaum Associates, Mahway, NJ, USA, 3rd edition, 1996.

[15] J. Dallongeville, J. R. Banegas, F. Tubach et al., "Survey of physicians' practices in the control of cardiovascular risk factors: the EURIKA study," European Journal of Cardiovascular Prevention and Rehabilitation. In press.

[16] M. N. M. van Poppel, M. J. M. Chinapaw, L. B. Mokkink, W. van Mechelen, and C. B. Terwee, "Physical activity questionnaires for adults: a systematic review of measurement properties," Sports Medicine, vol. 40, no. 7, pp. 565-600, 2010.

[17] P. Puska, "Nutrition and mortality: the Finnish experience," Acta Cardiologica, vol. 55, no. 4, pp. 213-220, 2000.

[18] J. L. Probstfield, "Prevention of stroke by antihypertensive drug treatment in older persons with isolated systolic hypertension: final results of the Systolic Hypertension in the 
Elderly Program (SHEP)," Journal of the American Medical Association, vol. 265, no. 24, pp. 3255-3264, 1991.

[19] V. J. Stevens, E. Obarzanek, N. R. Cook et al., "Long-term weight loss and changes in blood pressure: results of the trials of hypertension prevention, phase II," Annals of Internal Medicine, vol. 134, no. 1, pp. 1-11, 2001. 


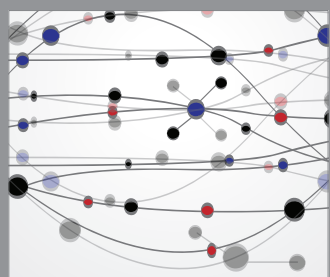

The Scientific World Journal
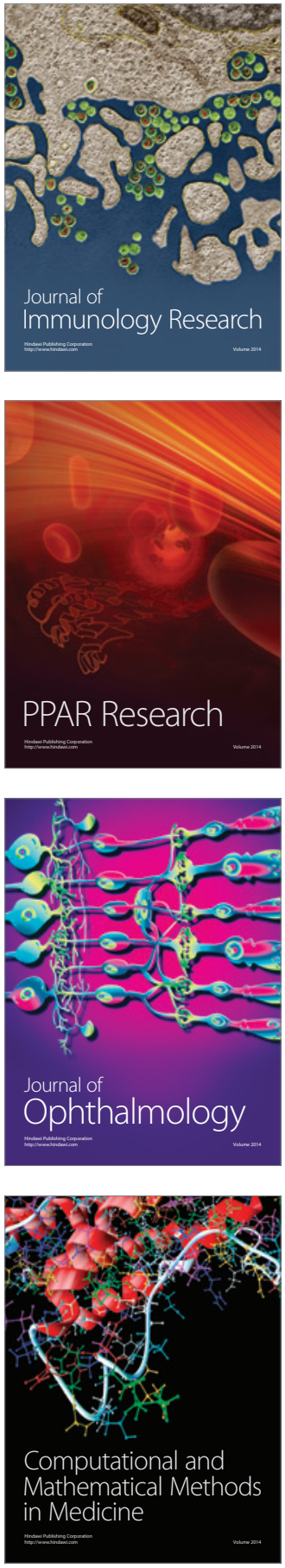

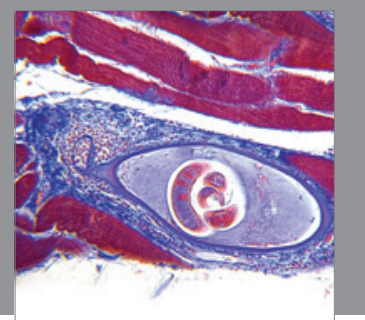

Gastroenterology

Research and Practice
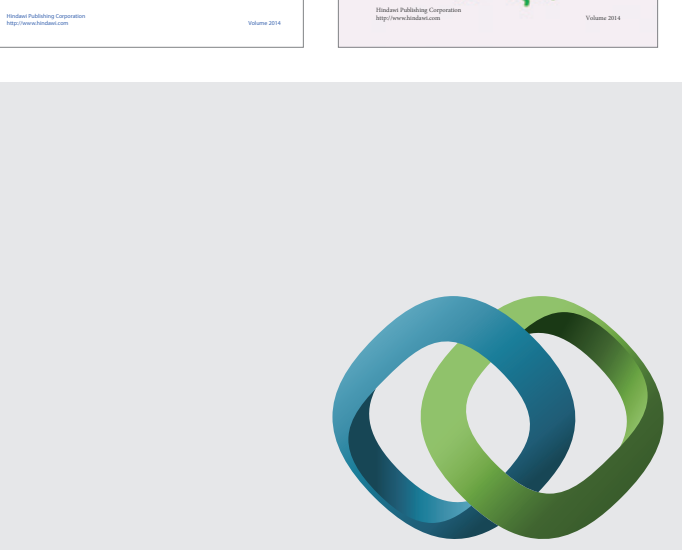

\section{Hindawi}

Submit your manuscripts at

http://www.hindawi.com
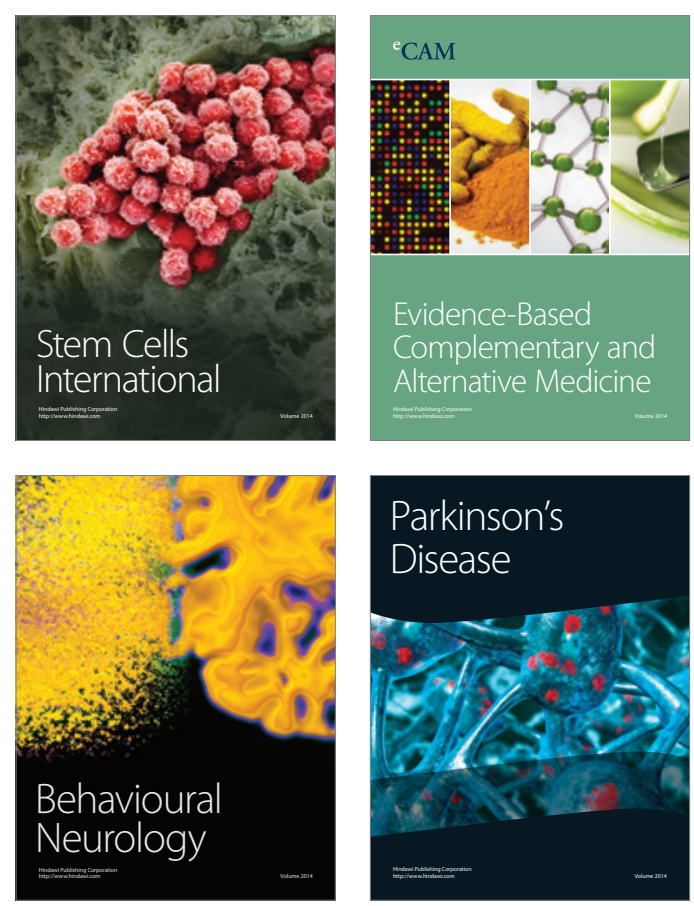

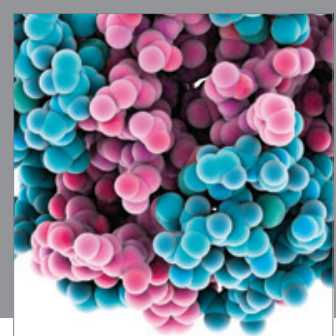

Journal of
Diabetes Research

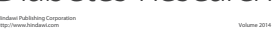

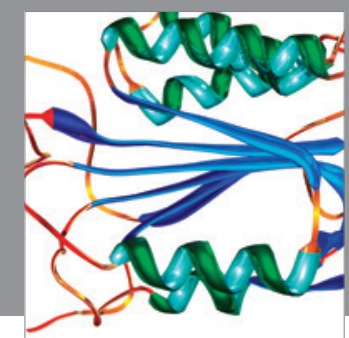

Disease Markers
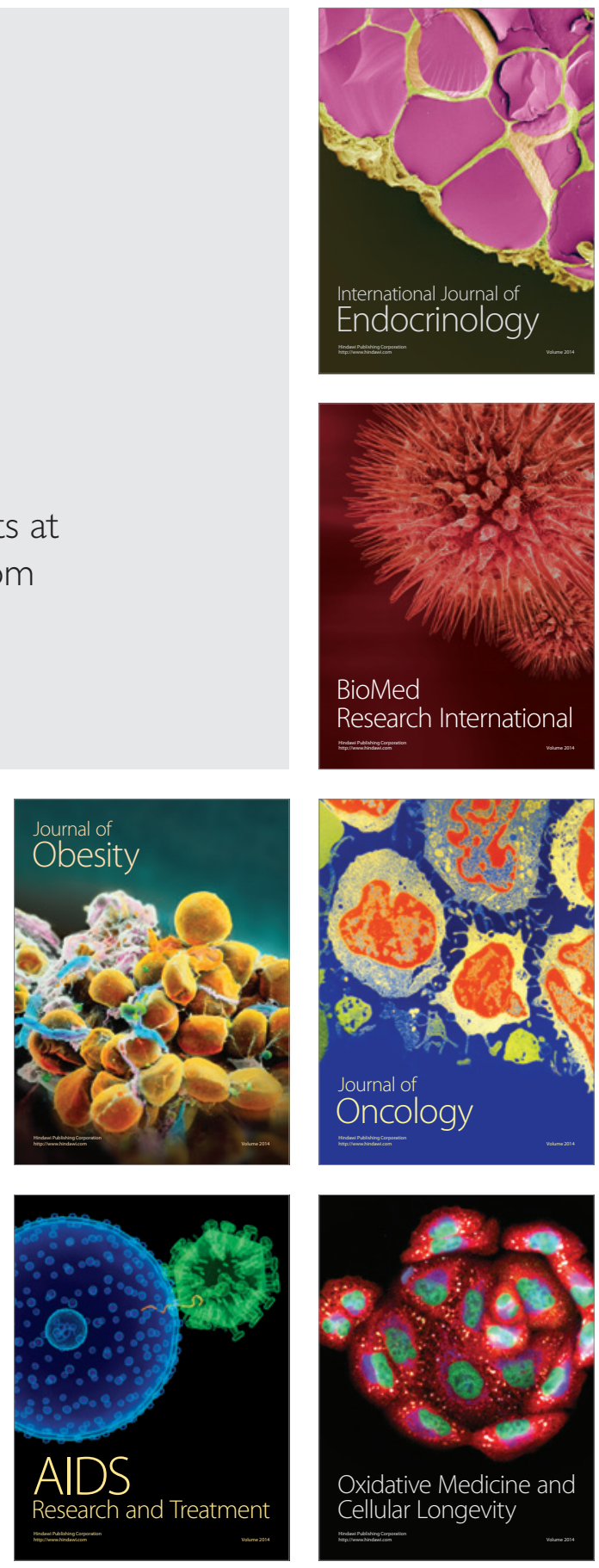